\title{
Contribution of sex-based immunological differences to the enhanced immune response in female mice following vaccination with hepatitis $B$ vaccine
}

\author{
MENG LI ${ }^{1 *}$, YUWEI ZHAO ${ }^{1 *}$, XUE CHEN $^{1 *}$, XUEMEI FU ${ }^{1}$, WEN LI ${ }^{1}$, HUMIN LIU $^{1}$, YUFANG DONG $^{1}$, \\ CHUANYAO LIU ${ }^{1}$, XIAO ZHANG ${ }^{1}$, LI SHEN $^{1}$, BING LI $^{2}$ and YAOMEI TIAN ${ }^{3}$ \\ ${ }^{1}$ Blood Research Laboratory, Chengdu Blood Center, Chengdu, Sichuan $610041 ;{ }^{2}$ General Clinic, \\ Affiliated Hospital of Inner Mongolia Agricultural University, Hohhot, Inner Mongolia Autonomous Region 010018; \\ ${ }^{3}$ College of Bioengineering, Sichuan University of Science and Engineering, Zigong, Sichuan 643000, P.R. China
}

Received August 25,2018; Accepted April 16, 2019

DOI: $10.3892 / \mathrm{mmr} .2019 .10231$

\begin{abstract}
Hepatitis B virus (HBV) vaccination is regarded as the most economical and effective method for the prevention and control of HBV infection, a major global health problem. Previous studies have suggested that there may be sex-specific differences regarding the immune response to the HBV vaccine in humans; however, the mechanisms associated with these sex-specific differences are yet to be elucidated. In the present study, sex-based immunological differences in mice following $\mathrm{HBV}$ vaccination were investigated to determine the mechanisms underlying sexual dimorphism, with the aim of identifying potential targets for clinical intervention. Balb/c mice $(n=6)$ were vaccinated intramuscularly on 3 different days (days 0, 14 and 28) with the HBV vaccine. Sera were analyzed via ELISA for the presence of HBV surface antigen (HBsAg)-specific immunoglobulin $\mathrm{G}$ (IgG), and of different IgG subtypes, 3 weeks following the third injection. Enzyme-linked immunosorbent spot assays were conducted to determine interleukin-4/interferon- $\gamma$ secretion. Immunological memory stimulated by the vaccine was detected via flow cytometry analysis and ELISA 1 week following the booster immunization. The seroconversion of the treated female group was higher compared with the male group at one week following the second vaccination. Female mice exhibited significantly increased
\end{abstract}

Correspondence to: Dr Yaomei Tian, College of Bioengineering, Sichuan University of Science and Engineering, 180 Xueyuan Road, Zigong, Sichuan 643000, P.R. China

E-mail: yaomei226@163.com

Dr Bing Li, General Clinic, Affiliated Hospital of Inner Mongolia Agricultural University, 306 Zhaowuda Road, Saihan, Hohhot, Inner Mongolia Autonomous Region 010018, P.R. China

E-mail: dazui7861@163.com

${ }^{*}$ Contributed equally

Key words: sexual dimorphism, hepatitis B vaccine, immune response
HBsAg antibody titers compared with males at 1-5 weeks following the third vaccination. Sera obtained from vaccinated female mice exhibited markedly increased titers of IgG1 and IgG2b compared with those from male mice. Furthermore, female mice exhibited elevated cytotoxic $\mathrm{T}$ lymphocyte responses and immune memory. Collectively, the results of the present study indicated that sex-based immunological differences affected the dynamics and characteristics of the immune response in mice immunized with the HBV vaccine.

\section{Introduction}

Hepatitis B virus (HBV) infection is a global health problem, particularly in Southeast Asia and Africa (1). An estimated 260 million individuals are chronic carriers, serving as the main reservoir for continued HBV transmission (2-4). Almost $25 \%$ of carriers develop serious liver diseases, including cirrhosis, chronic hepatitis and primary hepatocellular carcinoma (5). It is predicted that 500,000-1.2 million individuals succumb every year from the chronic consequences of HBV infection (6); however, the prevalence of HBV infection varies markedly between different countries. For example, the incidence rate is $15-20 \%$ in Taiwanese adults, 9.8\% in Egypt, $7.4 \%$ in Iran, $8.6 \%$ in Israel and $7.18 \%$ in China $(7,8)$.

Numerous countries introduced the HBV vaccine into national routine immunization schemes of infants during the 1990 s to eliminate HBV transmission and prevent HBV-associated chronic liver disease. The prevalence of HBV infection subsequently decreased in the following years, as the vaccination program was universally implemented (9). The universal HBV vaccination program for infants has been incorporated into the national immunization scheme in China since 1992 (10). Between 1992 and 2006, the surface antigen of HBV (HBsAg)-positive rate among young children in China decreased from $\sim 10 \%$ to $2.08 \%$ (11). High titers of HBV surface antibody (anti-HBs) produced in response to the HBV vaccine were revealed to be able to effectively protect humans from infection with HBV (12). At present, HBV vaccination is regarded as the most effective and economical method for the prevention and control of HBV infection $(11,13,14)$. 
Anti-HBs levels $\geq 10 \mathrm{IU} / 1$ in response to HBV vaccination are generally regarded as seroprotective, and are considered to effectively prevent HBV infection (15); however, due to interindividual differences, $5-10 \%$ of healthy immunocompetent subjects do not elicit an antibody response (16), notably increasing the possibility of HBV infection. A large number of clinical data have revealed that males exhibit an increased risk of non-responsiveness to the HBV vaccine (17-19). In addition, males are more likely than females to be HBV carriers, exhibit a notably increased mortality rate from hepatocellular carcinoma associated with HBV infection $(13,14,20)$, and HBV infection has been observed to be sexually dimorphic in humans (14). Consistent with these differences are sex-specific differences in the antibody response following vaccination; antibody responses are more easily stimulated in females than in males (21). At present, however, the mechanism underlying sex-based differences with respect to the anti-HBV immune response remains unclear. The present study aimed to determine the immunological differences in response to the HBV vaccine between immunized female and male mice, providing a potential theoretical framework for the prevention and control of HBV infection.

\section{Materials and methods}

Mice. A total of $72 \mathrm{BALB} / \mathrm{c}$ mice (36 males and 36 females, specific pathogen-free grade; aged 4-6 weeks; $13-15 \mathrm{~g}$ ) were purchased from Beijing Huafukang Biological Technology Co., Ltd. and housed in an aseptic environment at the Animal Center of State Key Laboratory of Biotherapy of Sichuan University for 2 weeks, with adaptive feeding prior to the start of experiment. The animals were fed with a standard laboratory chow and sterile water ad libitum. They were maintained in a controlled environment at a temperature of $20-25^{\circ} \mathrm{C}$, relative humidity of $40-70 \%$, artificially illuminated with a 12:12-h light/dark cycle and air exchanges of 10-15 times/h. The experimental protocol was approved by the Ethics Review Committee for Animal Experimentation of Chengdu Blood Center. A total of 3 cohorts of 24 mice were used during the present study; a preliminary cohort, and 2 experimental cohorts. Data from the second cohort were presented for ELISpot assays, whereas data for all other assays were generated from the third cohort.

Vaccines and immunization protocol. HBV vaccines were prepared by mixing $1 \mu \mathrm{g}$ HBsAg (cat. no. P4875; Abnova) with $25 \mu \mathrm{g}$ alum (cat. no. 21645-51-2; Brenntag Biosector A/S) in PBS in a total volume of $100 \mu \mathrm{l}$. BALB/c mice were randomly divided into four groups: Male control; female control; male treated and female treated. Treated groups $(n=6)$ were vaccinated 3 times intramuscularly with the HBV vaccine on days 0,14 and 28 . The mice in the control groups $(n=6)$ were treated with PBS. Blood samples were collected from the tail vein, with the exception of week 7 , when blood was collected via retro-orbital sampling under $4 \%$ isoflurane to obtain sufficient blood (150-200 $\mu$ l) to analyze total and subtype anti-HBs titers. Serum samples were obtained via centrifugation at $4,000 \mathrm{x} \mathrm{g}$ for $10 \mathrm{~min}$ at $4^{\circ} \mathrm{C}$ following incubation at $37^{\circ} \mathrm{C}$ for $2 \mathrm{~h}$. Sera were analyzed using ELISA for the presence of HBsAg-specific immunoglobulin $\mathrm{G}(\mathrm{IgG})$ at weeks 1, 3, 5 and 7. Enzyme-linked immunosorbent spot (ELISpot) assays were performed to determine the secreted levels of interleukin-4 (IL-4)/interferon- $\gamma$ $(\mathrm{IFN}-\gamma)$ at 1 week following the third immunization. Immunological memory stimulated by the vaccine was detected using flow cytometric analysis and ELISA at 1 week following the booster immunization (week 31 immunization; schematic of treatments in Fig. 1A).

Measurement of antibodies. HBsAg solution (100 $\mu \mathrm{l})$ diluted in carbonate buffer to a concentration of $1 \mu \mathrm{g} / \mathrm{ml}$ was applied to Nunc ${ }^{\mathrm{TM}}$ MaxiSorp ${ }^{\mathrm{TM}}$ 96-well flat-bottomed ELISA plates (BioLegend, Inc.) overnight at $4^{\circ} \mathrm{C}$. Following washing with 5\% (v/v) Tween-20 in PBS (pH 7.2; PBST), the plates were blocked with $5 \%$ non-fat dry milk and $0.05 \%$ Tween-20 in PBS for $1 \mathrm{~h}$ at $37^{\circ} \mathrm{C}$. The plates were subsequently incubated with 2-fold diluted serum from animals for $1 \mathrm{~h}$ at $37^{\circ} \mathrm{C}$. The initial dilution of serum for total $\operatorname{IgG}$ was set at 1:2,000, whereas that of the antibody subtype was 1:100. Plates were washed 5 times with PBST and subsequently detected with horseradish peroxidase-conjugated goat anti-mouse IgG (1:3,000 dilution; cat. no. ZB-2305; Beijing Zhongshan Golden Bridge Biotechnology Co., Ltd.; OriGene Technologies, Inc.), IgG1 (cat. no. 1070-05), IgG2a (cat. no. 1080-05) or IgG2b (cat. no. 1090-05; all 1:1,000 dilution; SouthernBiotech) for $1 \mathrm{~h}$ at $37^{\circ} \mathrm{C}$. Plates were developed using Thermo Scientific ${ }^{\mathrm{TM}}$ Pierce $^{\mathrm{TM}}$ 3,3',5,5'-tetramethylbenzidine substrate (cat. no. 34028; Pierce; Thermo Fisher Scientific, Inc.) for the peroxidase color reaction, followed by detection of the absorbance at $450 \mathrm{~nm}$ on an ELISA microplate reader.

Detection of seroconversion. Sera from weeks 1,3 and 5 were diluted to 1:100 with 5\% non-fat milk and 0.05\% Tween-30 in PBS, and subsequently analyzed for total anti-HBs IgG, following the aforementioned ELISA protocol. The calculation formula for the cut-off value was as follows: $2.1 \times\left[\mathrm{A}_{450}\right.$ (negative control)- $\mathrm{A}_{450}$ (blank)]. When the value of $\mathrm{A}_{450}$ (negative control)- $\mathrm{A}_{450}$ (blank) exceeded the cutoff value, the animals were classified as being anti-HBs seropositive. The seroconversion rate was determined as the percentage of anti-HBs seropositive mice in total immunized mice.

ELISpot assay. Splenocytes were isolated from immunized mice at 1 week following the final immunization as previously described (22), and ELISpot assays were performed using the mouse IFN- $\gamma /$ IL-4 Dual-Color ELISpot kit (cat. no. ELD5217; R\&D Systems, Inc.). Briefly, splenocytes $\left(5 \times 10^{5}\right.$ cells/well) were seeded in microplates that were pre-coated with mouse IFN- $\gamma$-specific monoclonal antibody and IL-4-specific polyclonal antibody. Subsequently, cells were co-incubated with $5 \mu \mathrm{g} / \mathrm{ml} \mathrm{HBsAg}$ or $1 \mu \mathrm{g} / \mathrm{ml}$ Concanavalin A (cat. no. 11028-71-0, Sigma-Aldrich; Merck KGaA) as a positive control at $37^{\circ} \mathrm{C}$ for $48 \mathrm{~h}$. ELISA analysis was then conducted according to the manufacturer's protocol. The spots were counted using an ELISpot reader system (Dakewe Biotech Co., Ltd.).

Flow cytometric analysis. A total of 3 treated mice were randomly selected to measure the percentage of memory $\mathrm{T}$ lymphocytes. Splenocytes were isolated from the immunized mice at week 32 and adjusted to $2 \times 10^{6}$ cells $/ \mathrm{ml}$. Splenic lymphocyte-suspending liquid $(100 \mu \mathrm{l})$ was added into the flow 

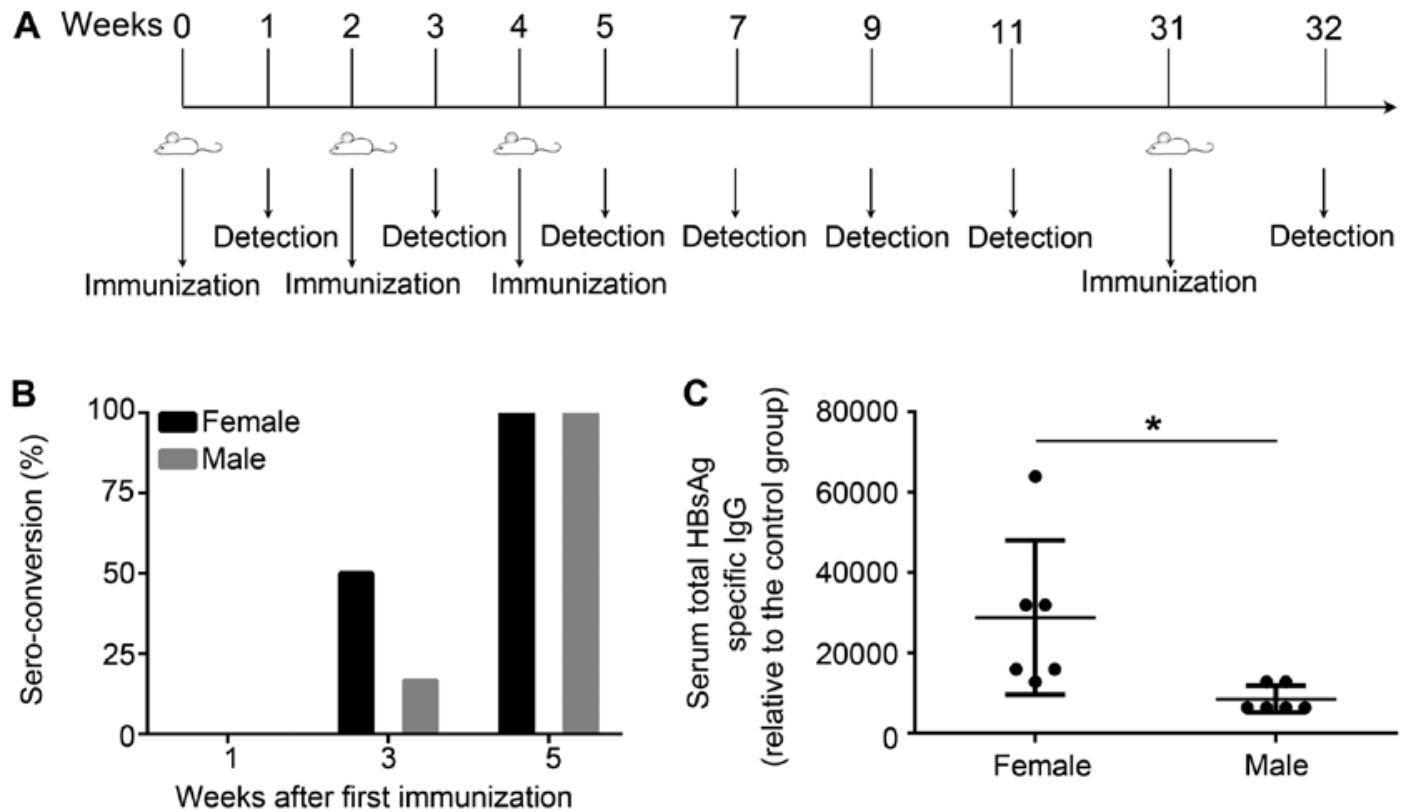

Figure 1. Induction of HBV immunity in mice. (A) Schematic of the HBV immunization protocol. Mice (n=6) were immunized with HBsAg $(1 \mu \mathrm{g})$ and alum $(25 \mu \mathrm{g})$ at weeks 0,2 and 4 , or treated with PBS as control. In addition, mice were immunized with the same dose of vaccine at week 31 . At 1 week following the third immunization, mice $(n=3)$ were sacrificed, and an enzyme-linked immunosorbent spot assay was performed. Sera were collected on weeks 1,3,5, 7, 9, 11 and 32, and the anti-HBs titers were measured by endpoint-dilution ELISA. The immunological memory stimulated by the vaccine was detected using flow cytometric analysis and ELISA at one week following the booster injection. For the measurement of antibodies, serum from the control groups was analyzed and used as the negative control. The positive cut-off for seroconversion was set as $2.1 \times\left[\left(\mathrm{OD}_{450}\right.\right.$ (negative control serum)-OD ${ }_{450}(\mathrm{blank}$ control)]. (B) Percentage of seroconversion for treated mice at weeks 0,2 and 4. (C) Total anti-HBs IgG titers measured one week following the third immunization. Data are presented as the mean \pm standard deviation. " $\mathrm{P}<0.05$ vs. male group. $\mathrm{HBV}$, hepatitis B virus; anti-HBs, hepatitis B surface antibody; OD, optical density; HBsAg, surface antigen of HBV; IgG, immunoglobulin G.

tube and centrifuged at $1,000 \mathrm{x}$ g for $5 \mathrm{~min}$ at $4^{\circ} \mathrm{C}$. The cells were blocked with $1 \mu 1$ anti-mouse cluster of differentiation (CD) $16 / \mathrm{CD} 32 \mathrm{mAb}$ (cat. no. 553141) in PBS for $5 \mathrm{~min}$ at $4^{\circ} \mathrm{C}$. Then cells were stained with peridinin-chlorophyll protein (perCP)-cyanine 5 (cy5)-anti-mouse CD4 (cat. no. 550954), perCP-cy5-anti-mouse CD8 (cat. no. 561109), phycoerythrin-anti-mouse CD44 (cat. no. 553134) and fluorescein isothiocyanate-anti-mouse CD62L (cat. no. 561917; $1 \mu 1$ of each antibody) for $30 \mathrm{~min}$ at $4^{\circ} \mathrm{C}$. All antibodies were purchased from BD Pharmingen (BD Biosciences). Then, the cells were washed twice with PBS. Stained cells were analyzed on a BD FACSCalibur ${ }^{\mathrm{TM}}$ flow cytometer (BD Biosciences). Flow cytometric analysis was performed using NovoExpress 1.2.1 software (ACEA Biosciences, Inc.).

Statistical analysis. Statistical analysis was performed using SPSS version 13.0 software (SPSS, Inc.). All values were presented as the mean \pm standard deviation. The independent-samples t-test was used for comparisons between treated groups. One-way ANOVA followed by Tukey's post hoc test was used for comparisons between multiple groups. $\mathrm{P}<0.05$ was considered to indicate a statistically significant difference.

\section{Results}

Seroconversion following $H B V$ vaccination. To investigate the seroconversion rate of anti-HBs, the prepared HBV vaccines were separately injected intramuscularly into the hind legs of female or male mice at 0,2 and 4 weeks, and subsequently the anti-HBs titers were detected at 1, 3 and 5 weeks (Fig. 1A).

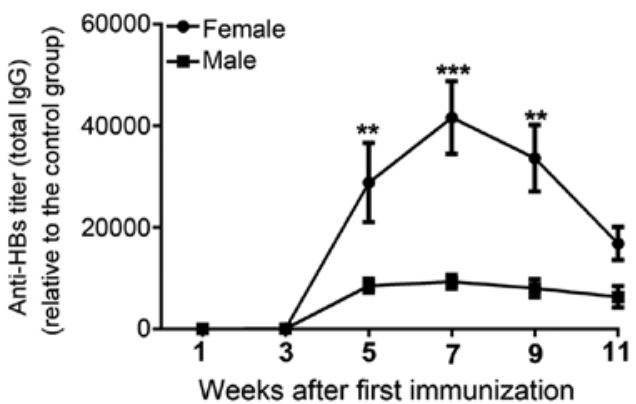

Figure 2. Anti-HBs levels following immunization over time. Levels of anti-HBs following immunization with the hepatitis $\mathrm{B}$ vaccine were measured at weeks 0,2 and 4 , relative to the PBS-treated control groups. Data are presented as the mean \pm standard deviation. ${ }^{* *} \mathrm{P}<0.01$ and ${ }^{* * *} \mathrm{P}<0.001$ vs. male group. Anti-HBs, hepatitis B surface antibody.

No changes in the immune response were elicited by the $\mathrm{HBV}$ vaccine in any of the mice at 1 week following the first immunization; however, 3 of the 6 female mice generated anti-HBs 1 week following the second immunization (a seroconversion rate of 50\%). Conversely, the seroconversion rate of the treated male mice group at this time point was $16.7 \%$ (Fig. 1B). A 100\% seroconversion rate was observed for the two treated groups following the third immunization; however, treated female mice produced a significantly increased total anti-HBs titer compared with the treated male mice (Fig. 1C).

Detection of increased levels of anti-HBs titer in treated female mice. It was previously reported that antibody responses 

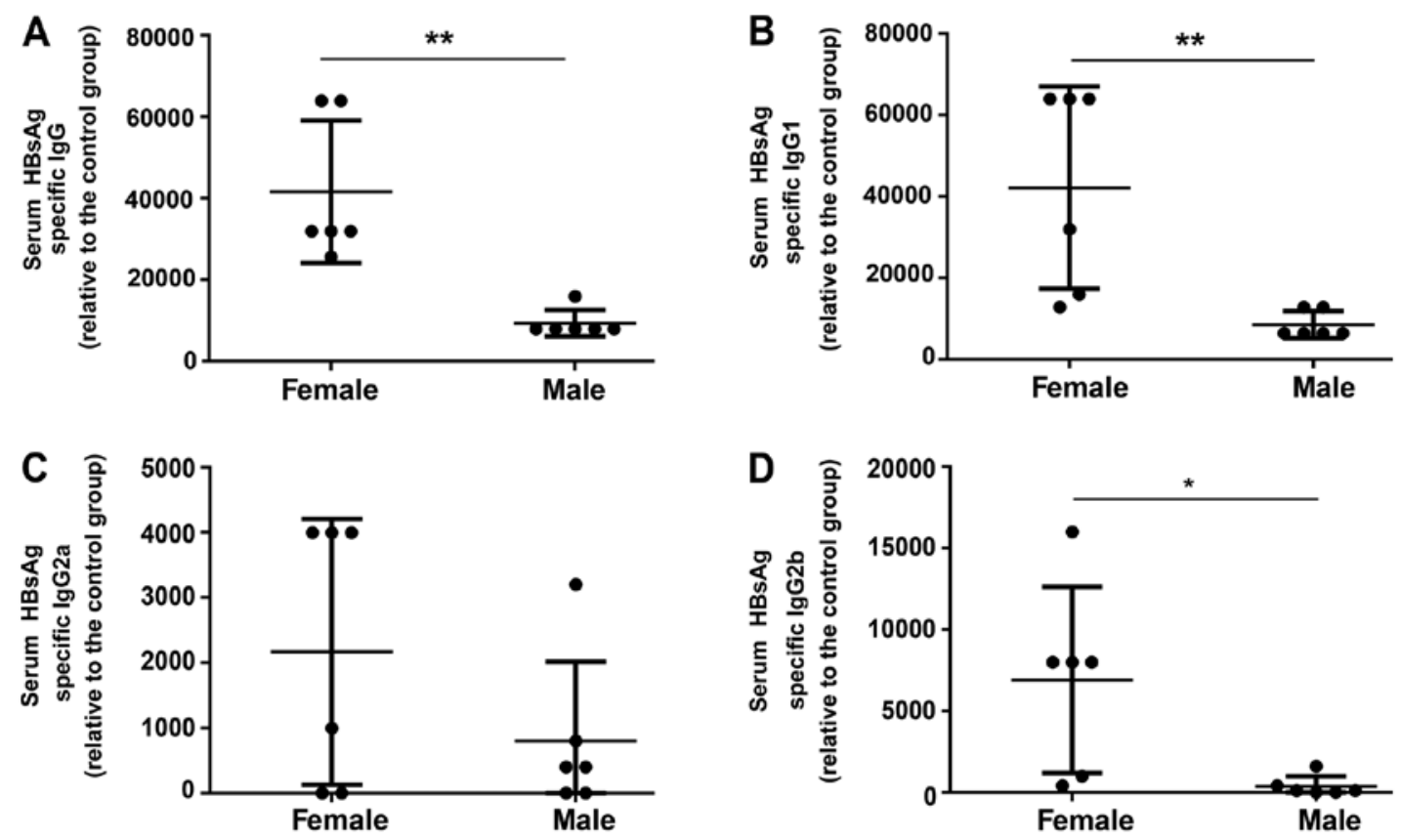

Figure 3. Detection of HBsAg-specific IgG subtypes. Titers of anti-HBs (A) IgG, (B) IgG1, (C) $\operatorname{IgG} 2 \mathrm{a}$ and (D) $\operatorname{IgG} 2 \mathrm{~b}$ were determined by ELISA at week 7 . Data are presented as the mean \pm standard deviation. ${ }^{*} \mathrm{P}<0.05,{ }^{* *} \mathrm{P}<0.01$ vs. male group. HBsAg, hepatitis B virus surface antigen; IgG, immunoglobulin $\mathrm{G}$.

to HBV vaccines were typically elevated in females compared with in males, particularly in young and elderly adult populations (12). To determine the effects of sex-specific differences on the efficacy of HBV vaccines, total anti-HBs titers were evaluated at 1, 3, 5, 7, 9 and 11 weeks following the first injection (Fig. 1A). The specific anti-HBs response was elicited in all immunized mice from week 3 compared with the control group (Fig. 2). In the treated female group, anti-HBs levels peaked at week 7 with a subsequent gradual reduction by weeks 9 and 11. Immune responses to the HBV vaccine were markedly increased in the treated female group compared with the treated males during the entire course of the experiment, and were significantly increased at weeks 5, 7 and 9 (Fig. 2).

Detection of increased levels of HBsAg-specific antibody subtypes in treated female mice. To further investigate the mechanisms of humoral immunity elicited by HBV vaccines, the expression of various subtypes of anti-HBs antibody were detected at week 7. Treated female mice produced a significantly increased total anti-HBs titer compared with the treated male mice at week 7 (Fig. 3A). Additionally, it was revealed that the $\mathrm{HBV}$ vaccine led to a non-significant trend towards an increased HBsAg-specific IgG2a titer in treated female mice compared with treated male mice (Fig. 3C). Furthermore, serum IgG1 (7.5-fold) and IgG2b (32-fold) levels were significantly increased in the treated female group compared with the treated male group (Fig. 3B and D). Collectively, the results indicated that compared with male mice, the $\mathrm{HBV}$ vaccine induced an increased antibody response in female mice.

Cytotoxic T lymphocyte (CTL) responses are increased in female mice compared with male mice. To further investigate the sex-based immunological differences between the female and the male mice, the production of IFN- $\gamma$ and IL- 4 by HBsAg-exposed splenocytes extracted from the immunized

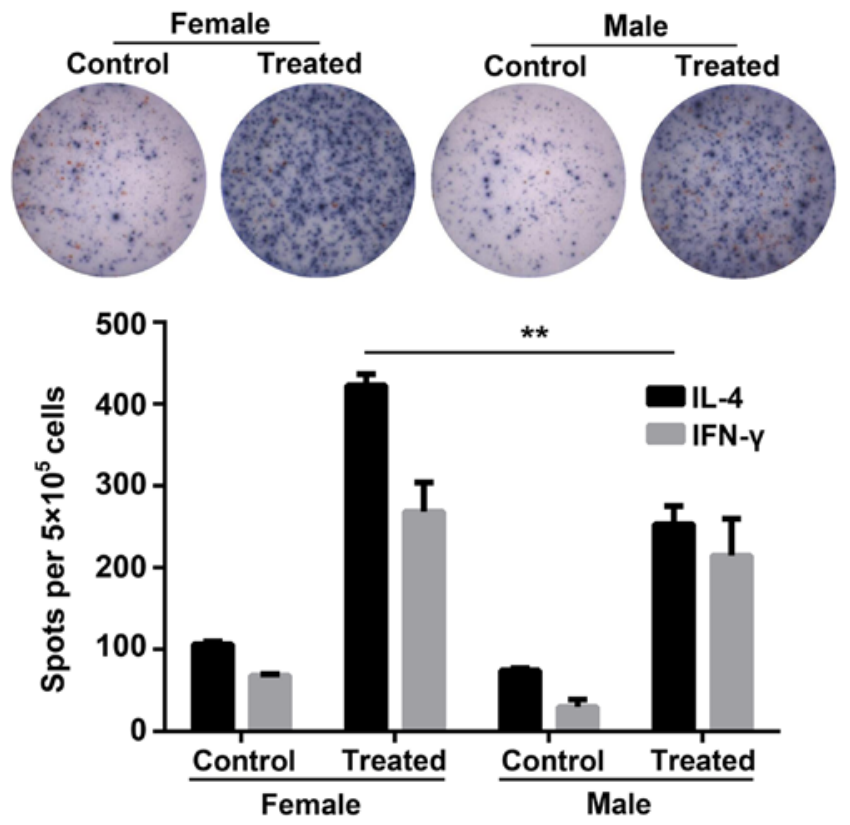

Figure 4. CTL responses to HBV immunization. Production of IL-4 (blue) and IFN- $\gamma$ (red) by CTLs 5 weeks following the first HBV immunization, as determined by an enzyme-linked immunosorbent spot assay. Data are presented as the mean \pm standard deviation. ${ }^{* *} \mathrm{P}<0.01$ vs. male treated group. CTL, cytotoxic T lymphocyte; HBV hepatitis B virus; IFN- $\gamma$, interferon- $\gamma$; IL-4, interleukin-4.

mice was detected via ELISpot assays in vitro. The number of IL-4 spot-forming cells (SFCs; blue; Fig. 4) was significantly increased in female mice compared with the treated males. Furthermore, the secretion of IFN- $\gamma$ (red SFCs) was markedly increased in treated female mice compared with treated males.

Female mice exhibit heightened immune memory compared with male mice. Memory lymphocytes capable of rapid 
A

Female
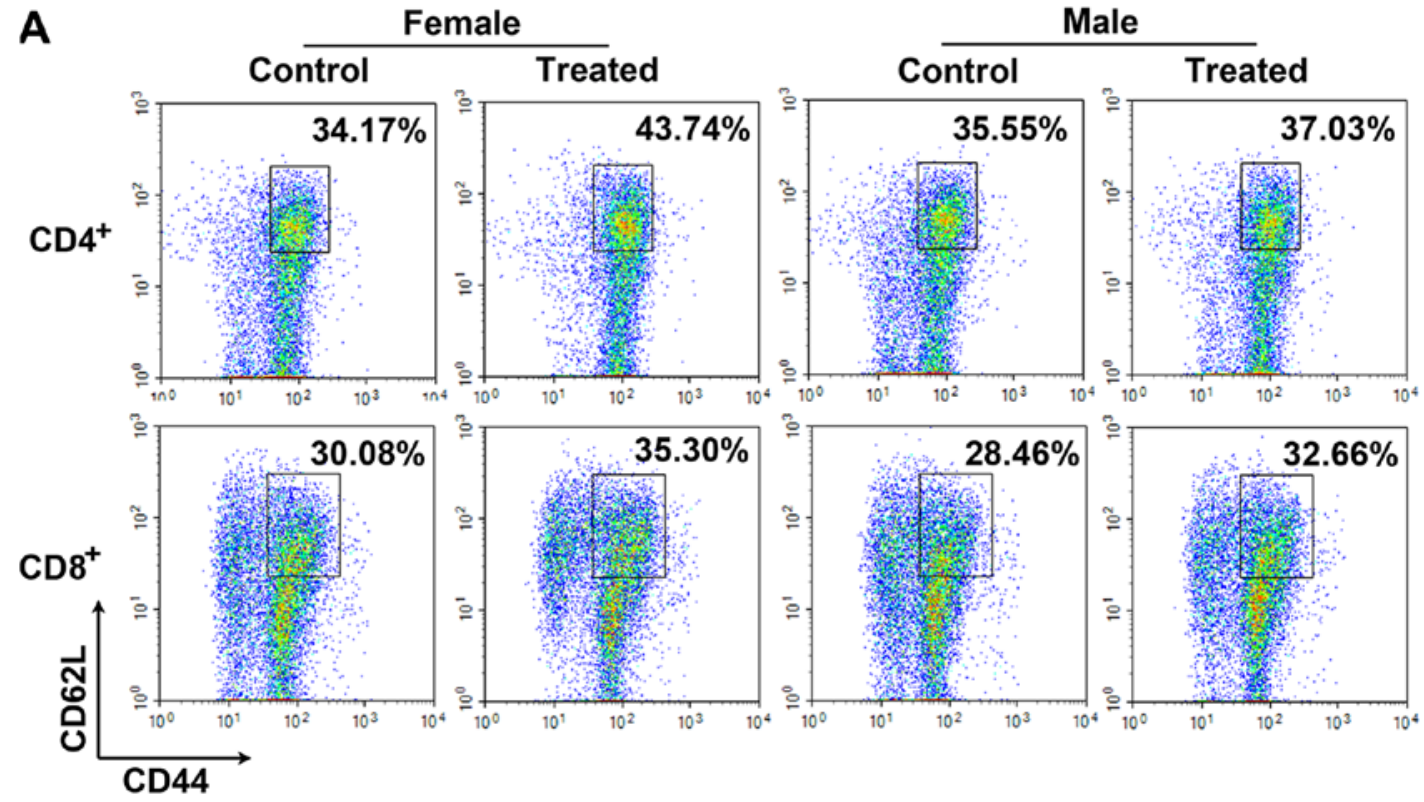

B

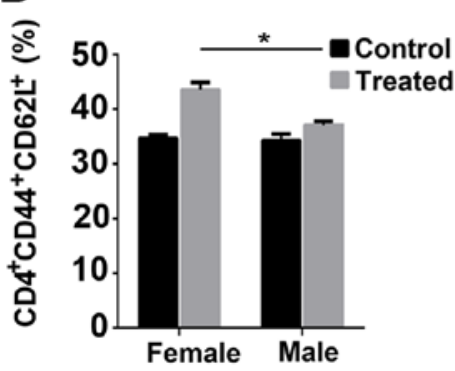

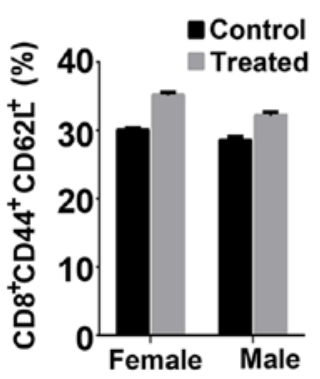

C

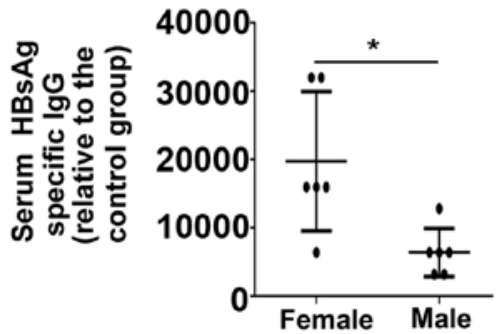

Figure 5. Detection of the immune memory responses. Gates for flow cytometry were set based on the corresponding control group using an isotype-stained control such that $<0.5 \%$ of cells were within the positive gate. (A) Representative plots and (B) quantification of percentages of $\mathrm{CD}^{+} / \mathrm{CD} 8^{+} \mathrm{CD} 44^{+} \mathrm{CD} 62 \mathrm{~L}^{+}$ cells, as determined by flow cytometry. (C) HBsAg-specific IgG titer detected at week 32 . Data are presented as the mean \pm standard deviation. * $\mathrm{P}<0.05$ vs. male treated group. CD, cluster of differentiation; HBsAg, hepatitis B surface antigen; IgG, immunoglobulin G.

proliferation or production of specific antibodies upon encountering HBV antigens serve an important role in suppressing HBV re-infection $(23,24)$. To determine the extent of long-term protection against $\mathrm{HBV}$, treated mice were injected with an HBV vaccine booster at week 31, and anti-HBs levels were detected one week later. A total of 3 treated mice were randomly selected to measure the percentage of memory $\mathrm{T}$ lymphocytes. As presented in Fig. 5A and B, treated female mice exhibited a significantly increased percentage of $\mathrm{CD} 4{ }^{+} \mathrm{CD} 44{ }^{+} \mathrm{CD} 62 \mathrm{~L}^{+}$ memory $\mathrm{T}$ cells compared with treated male mice. In addition, the anti-HBs titers in the treated female mice were significantly increased compared with the male mice (Fig. 5C).

Body weight. Age-matched Balb/c mice were randomly assigned to the aforementioned four treatment groups. Body weight was measured every week. Female and male treated mice exhibited normal body weights. There were no significant differences in body weight between the control and treated animals for either gender (Fig. 6).

\section{Discussion}

Infection with HBV, an acute and chronic communicable disease, has developed into a major global health

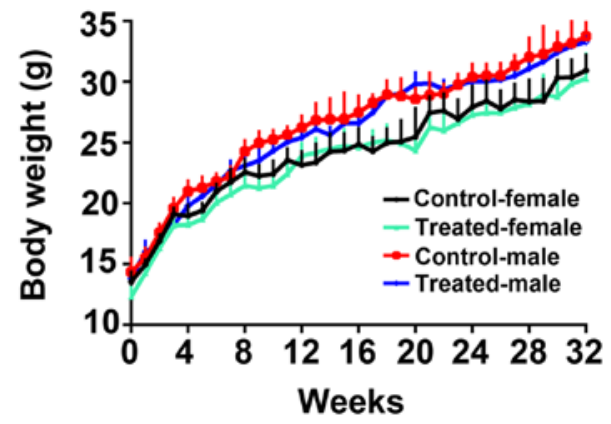

Figure 6. Body weight of control and hepatitis B-immunized mice. Body weight was measured every week for the duration of the study. Data are presented as the mean \pm standard deviation.

problem $(7,8,25)$. At present, vaccination is regarded as the most effective prevention measure against HBV infection; however, $\sim 5-10 \%$ of healthy immunocompetent subjects are non-responsive (26). Previous studies demonstrated that the male gender was associated with increased incidence of non-response to HBV vaccination $(19,25,27)$, whereas others indicated that there was no sex-based difference in the immune response to the HBV vaccine between males and 
females $(28,29)$. To clarify the biological influences of sex on the immune response to the HBV vaccine, the present study aimed to investigate the sexual dimorphism in the immune response to HBV vaccination in mice.

In the present study, sex-specific differences in antibody responses to the HBV vaccine were reported. Female mice exhibited an increased seroconversion rate in the early immunization stages, and sustained increased humoral immunity and cellular immunity compared with male mice. In addition, female mice developed a more effective immune memory that could rapidly induce high levels of anti-HBs or activate cellular immunity to clear HBV infection. Consistent with these results, sex-specific differences in the humoral immune response were previously observed with other vaccines, such as influenza, hepatitis B and meningococcal A (27). It was reported that females mount more frequent and stronger humoral and cell-mediated immune responses to bacterial and viral vaccines compared with males (30). According to certain studies (31-35), in addition to gender, the immunogenicity of the HBV vaccine was associated with age and body mass index; old age and excessive weight reduced the immune response to HBV vaccination. In the present study, mice of the same age were randomly divided into groups and body weight was measured every one week. There were no significant differences in body weight between the groups during the study period.

The results of the present study revealed that $~ 50 \%$ of the female mice were seropositive for anti-HBs antibody following two injections, compared with $16.7 \%$ of the male mice. Furthermore, the female mice developed more sustained, longer-lasting and significantly increased levels of anti-HBs following the second dose of HBV vaccine. The $\operatorname{IgG} 2 \mathrm{a}: \operatorname{IgG} 1$ antibody level ratio is frequently used to evaluate the type of $\mathrm{T}$ helper cell $(\mathrm{Th})$ response, with a value $>1$ indicating a predominantly Th1 response, and a value $<1$ indicating a predominantly Th2 response (36-38). To evaluate the type of immune response, the levels of total $\operatorname{IgG} 1, \operatorname{IgG} 2 \mathrm{a}$, and $\operatorname{IgG} 2 \mathrm{~b}$ were evaluated. The production of $\mathrm{IgG} 1$ and $\mathrm{IgG} 2 \mathrm{~b}$ antibodies in the female group was significantly increased compared with the male group, whereas no significant difference was observed between the two groups regarding IgG2a levels; however, this may be a result of the small sample size of the study $(\mathrm{n}=6)$, as relative IgG2a levels were notably increased in the female group compared with the male group. These findings suggested that the immune response evoked by HBV vaccine in the two treated groups was Th2-type.

The mechanisms underlying sex differences associated with antibody responses to vaccines remain unclear. It has been reported that an observed relative increase in $\mathrm{CD} 4^{+} \mathrm{T}$ cell numbers in females compared with males may partially explain the more vigorous antibody response in females $(39,40)$. In addition, increased levels of $\mathrm{T}$ cell activation and proliferation were previously detected in females compared with males when cultured peripheral blood mononuclear cells were stimulated in vitro $(41,42)$. HBV-specific CTLs and $\mathrm{CD} 4^{+} \mathrm{T}$ lymphocytes serve important roles in determining the outcome of HBV infection (43). Viral replication usually activates the $\mathrm{CD}^{+} \mathrm{CTL}$ response, which contributes towards the elimination of infected cells and reduced viral loads (44). Accompanying the development of the CTL response, $\mathrm{CD} 4^{+} \mathrm{T}$ cells proliferate and produce antiviral cytokines to regulate the immune response, preventing persistent infection by sustaining the $\mathrm{CD} 8^{+} \mathrm{CTL}$ function (45) or by providing signals for the induction of CD8 ${ }^{+} \mathrm{T}$-cell memory (46-49). To characterize the functional differences between the immune responses induced by HBV vaccination in mice of different sex, the production of the antiviral cytokines, IL-4 and IFN- $\gamma$, by HBsAg-exposed splenocytes from immunized mice was analyzed by an ELISpot assay. IFN- $\gamma$, predominantly secreted by $\mathrm{HBsAg}$-specific $\mathrm{CD} 8^{+} \mathrm{T}$ cells, but also by HBsAg-specific Th1 $\mathrm{CD}^{+} \mathrm{T}$ cells, is required for the elimination of HBV infection $(50,51)$. IL- 4 produced by $\mathrm{CD} 4{ }^{+} \mathrm{Th} 2$ cells contributes to B-cell development and the promotion of humoral responses; IL-4 was revealed to suppress the expression and replication of HBV in a hepatocellular carcinoma cell line (52). In the present study, the number of IL-4-secreting T cells was significantly increased in females compared with in males; however, the number of SFCs secreting IFN- $\gamma$ in females was not significantly different compared with in males.

HBV vaccination induces the production of a high titer of antibodies and an effective CTL response with the ability to eliminate HBV in immunized subjects (53); however, HBV-specific T-cell responses have a tendency to decline, even beyond the point of detection, in the years following vaccination (54). Therefore, the induction of immunological memory is required for achieving long-term protection (54). To characterize whether there were sexual differences in immune memory, in the present study, memory $\mathrm{T}$ cells were detected via flow cytometric analysis. The percentage of $\mathrm{CD} 4{ }^{+} \mathrm{CD} 44^{+} \mathrm{CD} 62 \mathrm{~L}^{+}$memory $\mathrm{T}$ cells was significantly increased in treated female mice compared with treated male mice; however, the percentage of $\mathrm{CD} 8{ }^{+} \mathrm{CD} 44^{+} \mathrm{CD} 62 \mathrm{~L}^{+}$ memory $\mathrm{T}$ cells was not significantly different between the two genders. Sex-dependent differences in immunological memory have also been reported in response to other vaccines (55). The anti-HBs titers in the treated female mice were increased compared with those in the treated male mice at one week following the booster injection. A limitation of the present study is that blood samples were not collected during week 31 , meaning that alterations in antibody titers prior to and following the booster could not be determined.

In conclusion, the present study may improve understanding of sexual dimorphism in the immune responses to $\mathrm{HBV}$ vaccine. Increasing evidence has indicated that biological sex influences the immune responses to vaccination and infection; however, the biological mechanisms underpinning such differences are yet to be determined $(30,56,57)$. Among the most well-established mechanisms for differences in immunity is the sex-hormone milieu. Therefore, further studies into the regulatory effects of sex hormones on the immune system are required.

\section{Acknowledgements}

We thank Professor Li Yang (State Key Laboratory of Biotherapy and Cancer Center, Sichuan University) for her assistance with experiments.

\section{Funding}

This work was supported by the Medical Research Program of Sichuan Medical Association (grant no. S16018). 


\section{Availability of data and materials}

The datasets used and/or analyzed during the current study are available from the corresponding author on reasonable request.

\section{Authors' contributions}

YT and BL made significant contributions to the design of the study, supervised the research and finalized the manuscript. $\mathrm{ML}, \mathrm{YZ}$ and $\mathrm{XC}$ performed the majority of the in vitro studies, and all of the in vivo experiments. ML drafted the manuscript. $\mathrm{CL}$ and $\mathrm{XZ}$ contributed to the analysis and interpretation of data. XF, WL, HL, YD and LS contributed to the design and coordination of experiments. All authors read and approved the final manuscript.

\section{Ethics approval and consent to participate}

The experimental protocol was approved by the Ethics Review Committee for Animal Experimentation of Chengdu Blood Center.

\section{Patient consent for publication}

Not applicable.

\section{Competing interests}

The authors declare that they have no competing interests.

\section{References}

1. Lavanchy D: Worldwide epidemiology of HBV infection, disease burden, and vaccine prevention. J Clin Virol 34 (Suppl 1): S1-S3, 2005.

2. O'Hara GA, McNaughton AL, Maponga T, Jooste P, Ocama P, Chilengi R, Mokaya J, Liyayi MI, Wachira T, Gikungi DM, et al: Hepatitis B virus infection as a neglected tropical disease. PLoS Neglect Trop Dis 11: e0005842, 2017.

3. Ott JJ, Stevens GA, Groeger J and Wiersma ST: Global epidemiology of hepatitis B virus infection: New estimates of age-specific HBsAg seroprevalence and endemicity. Vaccine 30: 2212-2219, 2012

4. Invernizzi F, Viganò M, Grossi G and Lampertico P: The prognosis and management of inactive HBV carriers. Liver Int 36 (Suppl 1): S100-S104, 2016.

5. Schweitzer A, Horn J, Mikolajczyk RT, Krause G and Ott JJ: Estimations of worldwide prevalence of chronic hepatitis B virus infection: A systematic review of data published between 1965 and 2013. Lancet 386: 1546-1555, 2015.

6. Lavanchy D: Hepatitis B virus epidemiology, disease burden, treatment, and current and emerging prevention and control measures. J Viral Hepat 11: 97-107, 2004.

7. Su FH, Cheng SH, Li CY, Chen JD, Hsiao CY, Chien CC, Yang YC, Hung HH and Chu FY: Hepatitis B seroprevalence and anamnestic response amongst Taiwanese young adults with full vaccination in infancy, 20 years subsequent to national hepatitis B vaccination. Vaccine 25: 8085-8090, 2007.

8. Melhem NM, Rahhal N, Charide R, Kreidieh K and El-Khatib R Human immunodeficiency virus and viral hepatitis among high-risk groups: Understanding the knowledge gap in the Middle East and North Africa Region. World J Hepatol 7: 2619-2630, 2015

9. Namgyal P: Impact of hepatitis B immunization, Europe and worldwide. J Hepatol 39 (Suppl 1): S77-S82, 2003.

10. Zhang C, Zhong Y and Guo L: Strategies to prevent hepatitis B virus infection in China: Immunization, screening, and standard medical practices. Biosci Trends 7: 7-12, 2013.
11. Huang YT, Jen CL, Yang HI, Lee MH, Su J, Lu SN, Iloeje UH and Chen CJ: Lifetime risk and sex difference of hepatocellular carcinoma among patients with chronic hepatitis B and C. J Clin Oncol 29: 3643-3650, 2011.

12. Sawyer LA: Antibodies for the prevention and treatment of viral diseases. Antiviral Res 47: 57-77, 2000.

13. Tanaka J, Kumagai J, Katayama K, Komiya Y, Mizui M, Yamanaka R, Suzuki K, Miyakawa Y and Yoshizawa H: Sex- and age-specific carriers of hepatitis B and C viruses in Japan estimated by the prevalence in the $3,485,648$ first-time blood donors during 1995-2000. Intervirology 47: 32-40, 2004.

14. Blumberg BS: The curiosities of hepatitis B virus: Prevention, sex ratio, and demography. Proc Am Thorac Soc 3: 14-20, 2006.

15. James L, Fong CW, Foong BH, Wee MK, Chow A, Shum E and Chew SK: Hepatitis B seroprevalence study 1999. Singapore Med J 42: 420-424, 2001.

16. Zuckerman JN: Protective efficacy, immunotherapeutic potential, and safety of hepatitis B vaccines. J Med Virol 78: 169-177, 2006.

17. Vermeiren AP, Hoebe CJ and Dukers-Muijrers NH: High non-responsiveness of males and the elderly to standard hepatitis B vaccination among a large cohort of healthy employees. J Clin Virol 58: 262-264, 2013.

18. Yen $\mathrm{YH}$, Chen $\mathrm{CH}$, Wang JH, Lee CM, Changchien CS and Lu SN: Study of hepatitis B (HB) vaccine non-responsiveness among health care workers from an endemic area (Taiwan). Liver Int 25: 1162-1168, 2005.

19. Yang S, Tian G, Cui Y, Ding C, Deng M, Yu C, Xu K, Ren J, Yao J, Li Y, et al: Factors influencing immunologic response to hepatitis B vaccine in adults. Sci Rep 6: 27251, 2016.

20. El-Serag HB: Epidemiology of viral hepatitis and hepatocellular carcinoma. Gastroenterology 142: 1264-1273.e1, 2012.

21. Klein SL and Flanagan KL: Sex differences in immune responses. Nat Rev Immunol 16: 626-638, 2016.

22. Camoglio L, Te Velde AA, de Boer A, ten Kate FJ, Kopf M and van Deventer SJ: Hapten-induced colitis associated with maintained Th1 and inflammatory responses in IFN-gamma receptor-deficient mice. Eur J Immunol 30: 1486-1495, 2000.

23. Banatvala J, Van Damme P and Oehen S: Lifelong protection against hepatitis B: The role of vaccine immunogenicity in immune memory. Vaccine 19: 877-885, 2000.

24. Zhu CL, Liu P, Chen T, Ni Z, Lu LL, Huang F, Lu J, Sun Z and Qu C: Presence of immune memory and immunity to hepatitis B virus in adults after neonatal hepatitis B vaccination. Vaccine 29: 7835-7841, 2011.

25. Karatekin G, Kilinç M, Gulcan Öksuz B and Iğde M: Hepatitis B seroprevalence in children and women and the impact of the hepatitis B vaccination program in the Black Sea Region of Turkey. J Infect Dev Ctries 7: 960-965, 2013.

26. Mast EE, Margolis HS, Fiore AE, Brink EW, Goldstein ST, Wang SA, Moyer LA, Bell BP and Alter MJ; Advisory Committee on Immunization Practices (ACIP): A comprehensive immunization strategy to eliminate transmission of hepatitis B virus infection in the United States: Recommendations of the Advisory Committee on Immunization Practices (ACIP) part 1: Immunization of infants, children, and adolescents. MMWR Recomm Rep 54: 1-31, 2005.

27. Cook IF: Sexual dimorphism of humoral immunity with human vaccines. Vaccine 26: 3551-3555, 2008.

28. Rezaei M, Nooripoor S, Ghorbani R, Ramezanshams F, Mamishi S and Mahmoudi S: Seroprotection after hepatitis B vaccination in children aged 1 to 15 years in central province of Iran, Semnan. J Prev Med Hyg 55: 1-3, 2014.

29. Al-Shamahy HA, Hanash SH, Rabbad IA, Al-Madhaji NM and Naser SM: Hepatitis B vaccine coverage and the immune response in Children under ten years old in Sana'a, Yemen. Sultan Qaboos Univ Med J 11: 77-82, 2011.

30. Klein SL, Jedlicka A and Pekosz A: The Xs and Y of immune responses to viral vaccines. Lancet Infect Dis 10: 338-349, 2010.

31. Tohme RA, Awosika-Olumo D, Nielsen C, Khuwaja S, Scott J, Xing J, Drobeniuc J, Hu DJ, Turner C, Wafeeg T, et al: Evaluation of hepatitis B vaccine immunogenicity among older adults during an outbreak response in assisted living facilities. Vaccine 29: 9316-9320, 2011.

32. Bender TJ, Sharapov U, Utah O, Xing J, Hu D, Rybczynska J, Drobeniuc J, Kamili S, Spradling PR and Moorman AC: Hepatitis B vaccine immunogenicity among adults vaccinated during an outbreak response in an assisted living facility-Virginia, 2010. Vaccine 32: 852-856, 2014. 
33. Zeeshan M, Jabeen K, Ali AN, Ali AW, Farooqui SZ, Mehraj V and Zafar A: Evaluation of immune response to Hepatitis B vaccine in health care workers at a tertiary care hospital in Pakistan: An observational prospective study. BMC Infect Dis 7: $120,2007$.

34. Ingardia CJ, Kelley L, Steinfeld JD and Wax JR: Hepatitis B vaccination in pregnancy: Factors influencing efficacy. Obstet Gynecol 93: 983-986, 1999.

35. Sangfelt P, Uhnoo I, Reichard O and Weiland O: A low-dose intradermal hepatitis B vaccine programme in health-care workers and students is highly effective and cost saving: A retrospective follow-up survey in the clinical setting. Scand J Gastroenterol 43: 465-472, 2008

36. Collins JT and Dunnick WA: Germline transcripts of the murine immunoglobulin gamma $2 \mathrm{a}$ gene: Structure and induction by IFN-gamma. Int Immunol 5: 885-891, 1993.

37. Cher DJ and Mosmann TR: Two types of murine helper T cell clone. II. Delayed-type hypersensitivity is mediated by TH1 clones. J Immunol 138: 3688-3694, 1987.

38. Carcaboso AM, Hernandez RM, Igartua M, Rosas JE, Patarroyo ME and Pedraz JL: Potent, long lasting systemic antibody levels and mixed Th1/Th2 immune response after nasal immunization with malaria antigen loaded PLGA microparticles. Vaccine 22: 1423-1432, 2004

39. Bede P, Elamin M, Byrne S and Hardiman O: Sexual dimorphism in ALS: Exploring gender-specific neuroimaging signatures. Amyotroph Lateral Scler Frontotemporal Degener 15: 235-243, 2014.

40. Lisse IM, Aaby P, Whittle H, Jensen H, Engelmann M and Christensen LB: T-lymphocyte subsets in West African children: Impact of age, sex, and season. J Pediatr 130: 77-85, 1997.

41. Sankaran-Walters S, Macal M, Grishina I, Nagy L, Goulart L, Coolidge K, Li J, Fenton A, Williams T, Miller MK, et al: Sex differences matter in the gut: Effect on mucosal immune activation and inflammation. Biol Sex Differ 4: 10, 2013.

42. Abdullah M, Chai PS, Chong MY, Tohit ER, Ramasamy R, Pei CP and Vidyadaran S: Gender effect on in vitro lymphocyte subset levels of healthy individuals. Cell Immunol 272: 214-219, 2012.

43. Rehermann B and Nascimbeni M: Immunology of hepatitis B virus and hepatitis $C$ virus infection. Nat Rev Immunol 5: 215-229, 2005 .

44. Kägi D, Ledermann B, Bürki K, Zinkernagel RM and Hengartner H: Molecular mechanisms of lymphocyte-mediated cytotoxicity and their role in immunological protection and pathogenesis in vivo. Annu Rev Immunol 14: 207-232, 1996.
45. Brooks DG, Teyton L, Oldstone MB and McGavern DB: Intrinsic functional dysregulation of CD4 T cells occurs rapidly following persistent viral infection. J Virol 79: 10514-10527, 2005.

46. Janssen EM, Lemmens EE, Wolfe T, Christen U, von Herrath MG and Schoenberger SP: CD4 ${ }^{+} \mathrm{T}$ cells are required for secondary expansion and memory in $\mathrm{CD}^{+} \mathrm{T}$ lymphocytes. Nature 421: 852-856, 2003.

47. Shedlock DJ and Shen H: Requirement for CD4 T cell help in generating functional CD8 T cell memory. Science 300: 337-339, 2003.

48. Lee BW, Yap HK, Chew FT, Quah TC, Prabhakaran K, Chan GS, Wong SC and Seah CC: Age- and sex-related changes in lymphocyte subpopulations of healthy Asian subjects: From birth to adulthood. Cytometry 26: 8-15, 1996.

49. Uppal SS, Verma S and Dhot PS: Normal values of CD4 and CD8 lymphocyte subsets in healthy indian adults and the effects of sex, age, ethnicity, and smoking. Cytometry B Clin Cytom 52: 32-36, 2003.

50. Webster GJ, Reignat S, Maini MK, Whalley SA, Ogg GS, King A, Brown D, Amlot PL, Williams R, Vergani D, et al: Incubation phase of acute hepatitis B in man: Dynamic of cellular immune mechanisms. Hepatology 32: 1117-1124, 2000.

51. Mosmann TR and Coffman RL: Heterogeneity of cytokine secretion patterns and functions of helper T cells. Adv Immunol 46: 111-147, 1989

52. Lin SJ, Shu PY, Chang C, Ng AK and Hu CP: IL-4 suppresses the expression and the replication of hepatitis $\mathrm{B}$ virus in the hepatocellular carcinoma cell line Hep3B. J Immunol 171: 4708-4716, 2003.

53. Chang MH, You SL, Chen CJ, Liu CJ, Lai MW, Wu TC, Wu SF, Lee CM, Yang SS, Chu HC, et al: Long-term effects of hepatitis B immunization of infants in preventing liver cancer. Gastroenterology 151: 472-480.e1, 2016.

54. Shepard CW, Simard EP, Finelli L, Fiore AE and Bell BP Hepatitis B virus infection: Epidemiology and vaccination. Epidemiol Rev 28: 112-125, 2006.

55. Voysey M, Barker CI, Snape MD, Kelly DF, Trück J and Pollard AJ: Sex-dependent immune responses to infant vaccination: An individual participant data meta-analysis of antibody and memory B cells. Vaccine 34: 1657-1664, 2016.

56. Furman D, Hejblum BP, Simon N, Jojic V, Dekker CL, Thiébaut R, Tibshirani RJ and Davis MM: Systems analysis of sex differences reveals an immunosuppressive role for testosterone in the response to influenza vaccination. Proc Natl Acad Sci USA 111: 869-874, 2014.

57. Jørgensen TN: Sex disparities in the immune response. Cell Immunol 294: 61-62, 2015. 